\title{
Effect of Words Highlighting in School Tasks upon Typical ADHD Behaviors
}

\author{
Waleska Mascarenhas dos Santos* (1) \& Alessandra Rocha de Albuquerque (D) \\ Universidade Católica de Brasília, Brasília, DF, Brasil
}

\begin{abstract}
RESUMO - Intervenções em sala de aula são relevantes para o processo educacional de estudantes com TDAH. É nesse contexto que comportamentos típicos do transtorno são especialmente problemáticos e contribuem para altos índices de fracasso e evasão escolar. O presente estudo teve por objetivo analisar o efeito do destaque de palavras sobre a desatenção e hiperatividade/impulsividade de três estudantes do Ensino Fundamental com diagnóstico de TDAH. Foi utilizado um delineamento combinado de reversão e linha de base múltipla entre participantes. Observou-se a redução da frequência de ocorrência dos comportamentos de interesse adicionalmente ao maior percentual de acertos em tarefas com palavras destacadas. Os resultados replicam e ampliam os de pesquisas anteriores. Propõe-se a aplicação da intervenção com diferentes conteúdos e tarefas.
\end{abstract}

PALAVRAS-CHAVE: TDAH, intervenções escolares, intervenções comportamentais, sala de aula

\section{Efeito do Destaque de Palavras em Tarefas Escolares sobre Comportamentos Típicos do TDAH}

\begin{abstract}
Behavioral interventions in classroom are relevant to the educational process of students with ADHD. It is in this context that typical disorder's behaviors are especially problematic and contribute to high rates of school failure and dropout. The aim of the present study was to analyze the effect of word highlighting on inattention and hyperactivity/ impulsivity of three elementary students with ADHD. A multiple baseline design combined with a reversal design was used. Reduction in the frequency of the behaviors of interest and higher frequency of correct answers in school tasks were observed when words were highlighted. The results replicate and extend data of previous studies. The application of the intervention with different contents and tasks is proposed.
\end{abstract}

KEYWORDS: ADHD, school interventions, behavioral interventions, classroom

Attention-deficit hyperactivity disorder (ADHD) is characterized by a persistent pattern of a triad of inattentive, hyperactive, and impulsive behaviors (American Psychiatric Association - APA, 2014; World Health Organization WHO, 2016). These behaviors can occur with varying intensities, from mild to severe, with different functional impairment (Barkley, 2002; Mattos, 2015).

The worldwide prevalence of the disorder is estimated to be around $3 \%$ and $6 \%$ of the child population (APA, 2014). In Brazil, rates of $4.4 \%$ were pointed out by an epidemiological research (Arruda et al., 2010), which also indicated a higher prevalence among low-income boys, corroborating results of previous researches (Fontana et al., 2007; Vasconcelos et al., 2003).

In the educational context, students with ADHD are often seen as "problem students". These students have poor school performance and have double or triple the risk of school failure compared to other students. This situation culminates in repetition and dropout rates around 35\% in high school (Barkley, 2002; Dorneles et al., 2014).

*E-mail: waleskanathalia@gmail.com

- Submetido: 20/07/2017; Aceito: 19/09/2019. 
Recently, ADHD has been understood as a multifactorial disorder that requires multimodal intervention (Araújo et al., 2013; Costa et al., 2015). However, unlike this proposition, the prescription of exclusively pharmacological interventions is frequent and the consumption of drugs for this purpose is increasing (Moysés \& Collares, 2013). Leonardi and Rubano (2012) carried out a search of articles referring to behavioral treatment of ADHD, published over the period of 40 years (from 1968 to 2007), in the Journal of Applied Behavior Analysis (JABA). Only 25 articles were found. Although the focus of JABA is the publication of applied research involving behavioral principles, some of these articles $(\mathrm{N}$ $=4$ ) reported investigations about the exclusive effects of stimulating drugs on the repertoire of people diagnosed with ADHD while others $(\mathrm{N}=9)$ manipulated stimulating drugs as one of the independent variables. Only seven articles reported research conducted in the classroom.

These data illustrate the small number of on-site researches in the classroom, emphasizing educational practices aimed at promoting learning, preventing failure, and dropping out of school. For Vasconcelos (2002), the school difficulties of children with ADHD must be addressed in the classroom context, which must be organized to benefit the adaptation and learning of these children. It is up to the teacher to plan differentiated and organized educational practices, to establish strategies and contingencies that promote effective learning of these students (Santos \& Vasconcelos, 2010; Skinner, 1968/1972).

Considering classroom as an important and differentiated intervention context, the United States Department of Education (Planty et al., 2008) recommends the use of behavioral strategies to teach children with ADHD. The department points out that programs aimed at these students should integrate academic instruction, behavioral interventions, and accommodation in the classroom.

Behavioral interventions involve contingency management and, therefore, comprise "at least three strategic approaches: altering antecedent variables, altering consequent variables, and teaching alternative behaviors" (Cooper et al., 2007, p. 502). Interventions focusing on the antecedent variables fall into the study field of stimulus control (Dinsmoor, 1995a, 1995b; Sério et al., 2004). Such control is affected by different variables, such as: sensory capacity of organisms, type of reinforcement used and response required, disparity of stimuli, and relative salience of stimuli (Domjan, 2010). The disparity and salience of a positive stimulus are defined, respectively, as the magnitude of the difference between that stimulus and a negative stimulus and the background stimulus (Dinsmoor, 1995b). The salience of stimuli can be changed, through prompts or tips, to favor the occurrence of desired behaviors and to minimize errors in discriminative tasks (Mitenberger, 2012).
A commonly used strategy of manipulating stimuli salience, in investigations with students with ADHD, is the use of highlighting the color of relevant stimuli as a prompt (e.g., Belfiore et al., 1996; Kercood \& Grskovik, 2009; Kercood et al., 2012; Zentall et al., 2000). Zentall et al. (2000) evaluated the effect of the use of color in standardized tests on maintaining attention and reading performance of 25 students with and without attention deficit. Two individual sessions were held with all participants. In the first session, half of the participants were exposed to the text written in black and the other half to the text highlighted in colors in three diverse ways: the first third of the text was presented in black; the second third highlighted in pastel colors; and the last third in bold and intense colors. In the second session, the experimental conditions were reversed among the participants. The results showed accurate performances of children with and without attention deficit when colors were used and a greater number of errors of children with attention deficit in the black text condition.

Like the study described, others have used color highlighting to promote and maintain selective (e.g., Belfiore et al., 1996; Kercood \& Grskovic, 2009; Kercood et al., 2012; Zentall et al., 1985) and sustained attention (e.g., Zentall \& Dwyer, 1988; Zentall \& Kruczek, 1988), and to establish mathematical (e.g., Kercood \& Grskovic, 2009; Kercood et al., 2012) and verbal repertoires (e.g., Belfiore et al., 1996; Imhof, 2004; Zentall et al., 2000; Zentall et al., 1985). These investigations aimed to reduce the probability of problem behaviors, thus having a preventive character (Kern et al., 2002). Such studies, however, were conducted predominantly with North American children, applied individually or in exclusive groups of children with ADHD and, in general, in contexts other than the classroom (e.g., resource room, meeting room, arts room).

The present study aimed to evaluate the effect of highlighting words (with the use of color in activity sheets) on behavior classes of inattention (e.g., failing to respond when asked, and losing objects) and hyperactivity/ impulsiveness (e.g., interrupting other people while speaking, and difficulty waiting for their turn) from low socioeconomic students diagnosed with ADHD. Unlike previous research (e.g., Kercood et al., 2012; Kercood \& Grskovic, 2009; Zentall et al., 2000), the intervention was applied in the classroom, with the whole class, involving the management of the behavior of all students, aiming to add integrative and inclusive characteristics to the intervention (Neef \& Northup, 2007). The integrative character refers to the fact that the students with ADHD have performed the same activities as the other students, together with them; the inclusive character is related to the fact that the intervention involved the choice of teaching strategies based on the specific needs of the students with ADHD. 


\section{METHOD}

\section{Participants}

Three students from the early years of Elementary Education in a public school in the Federal District in Brazil participated in the study. The participants, identified by fictitious names (Carlos, $1^{\text {st }}$ year; Bruno, $3^{\text {rd }}$ year; Fábio, $5^{\text {th }}$ year), were between six and 10 years old (Table 1). They were nominated by the school manager and teachers to participate in the research since they presented a medical diagnose of ADHD, issued by an outside school professional. Additionally, to standardize the assessment of the participants regarding the diagnosis, the Attention Deficit Hyperactivity Disorder Scale - Version for Teachers (Benczik, 2015) was applied to all of them. Scores equal to or greater than 76 , in at least one of the three components (attention deficit, hyperactivity/impulsivity, and antisocial behavior) of the subscales of this instrument, was established as an inclusion criteria in the study. During the research period, none of the participants were using any medication.

\section{Setting}

Data collection took place in a public school in the Administrative Region of Ceilândia, in the Federal District, in the corresponding classroom of each participant, with the participation of the teacher and all other students in the class.

\section{Instruments}

Three sets of instruments were used: for initial assessment and selection of participants; for the application of the intervention and for the assessment of the effects of the intervention. The Attention Deficit and Hyperactivity Disorder Scale - Version for Teachers (Benczik, 2015) and a semi-structured interview script (for parents and teachers) were used to evaluate and select the participants.

For the application of the intervention, activity sheets that addressed the contents of Nature Sciences (animals at risk of extinction), corresponding to the school year of each participant, were created with the collaboration of the teachers. The activity sheets contained the animal fact file of an endangered animal and five questions related to it. Both in the fact file and in the questions, there were relevant words (for example, size, type of food, popular name) highlighted in yellow. In the fact file, some information about the animal that would constitute answers to the questions (for example, the animal's weight and popular name) was highlighted. In the questions, the words that made explicit the information to be provided in the answer were highlighted. Among the five questions, only three had a highlighted word. Figure 1 illustrates one of the forms used in the study.

Four activity sheets, each on an animal (blue-gray macaw, leatherback sea turtle, golden lion tamarin, black lion tamarin), were used with each participant. At each intervention session, a different activity sheet was used. The activity sheets used in the $1 \mathrm{st}$ and $3^{\text {rd }}$ year classes, by participants Carlos and Bruno, respectively, were identical and like the one shown in Figure 1. The activity sheets used in the $5^{\text {th }}$ year class, by Fábio, presented the same animals and fact file, however, in the topics "food" and "characteristics" a larger set of information was provided. In addition, there was no space for drawing the animal in the $5^{\text {th }}$ year activity sheets. The application of the activity sheets differed between the classes. In the $1^{\text {st }}$ year class, the reading of the activity sheet was mediated by the teacher; in the $3^{\text {rd }}$ and $5^{\text {th }}$ year, the reading was done independently by the students.

A systematic observation protocol of typical ADHD behaviors, developed by Araújo et al. $(2011,2013)$, was used to observe and record the behavior of the participants during the intervention sessions. The protocol operationally defined 16 typical ADHD behavior organized into five categories: inattention, easily distracted, restlessness, movement, and impulsiveness. The first two categories describe typical inattention behaviors and the last three describe typical hyperactivity/impulsivity behaviors. Table 2 presents this protocol.

Table 1

Characterization of the Participants

\begin{tabular}{lccccc}
\hline \multirow{2}{*}{ Participants } & Age & School Year & \multicolumn{3}{c}{ Percentile } \\
\cline { 4 - 6 } & & 1 At & 60 & Hyperactivity Impulsivity & Antisocial Behavior \\
\hline Carlos & $6 \mathrm{y} 4 \mathrm{~m}$ & $3 \mathrm{rd}$ & 85 & 90 & 85 \\
Bruno & $10 \mathrm{y} 4 \mathrm{~m}$ & 5 th & 55 & 80 & 60 \\
Fábio & $10 \mathrm{y} 8 \mathrm{~m}$ & & 55 & 90 \\
\hline
\end{tabular}




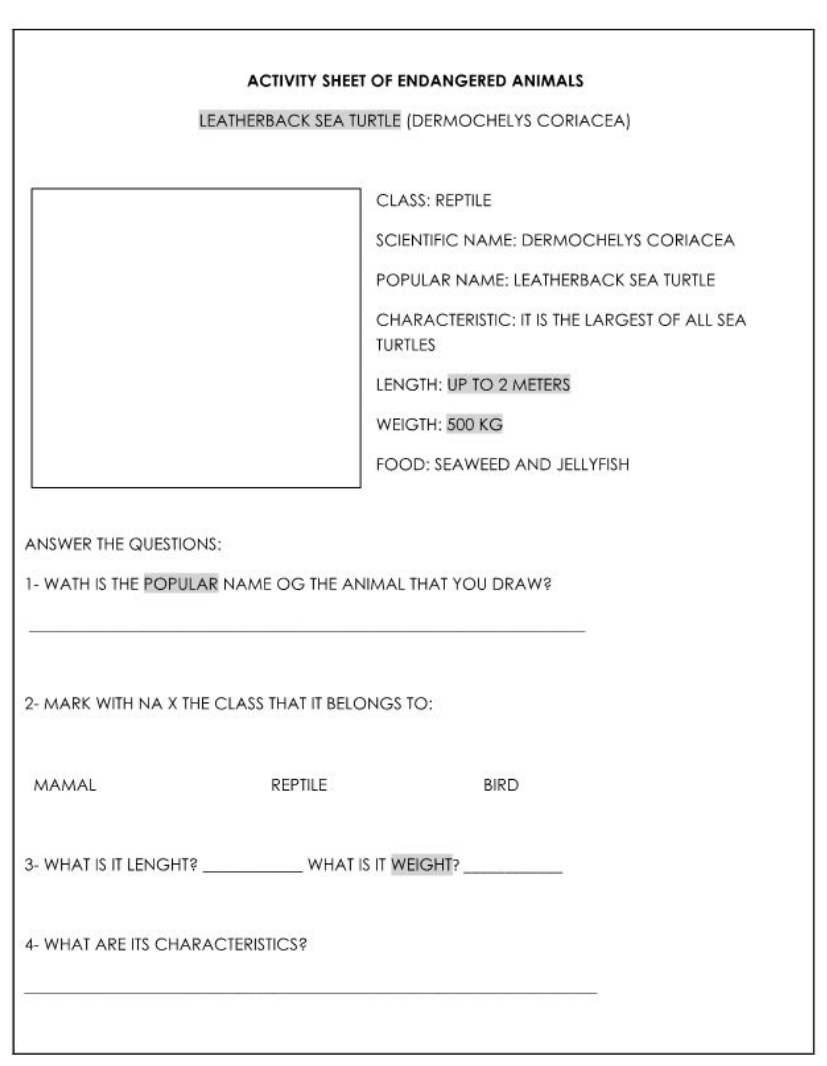

Figure 1. Example of an activity sheet used in the study. The shading over the words was originally yellow. The blank square was used for the child's drawing of the animal.

Based on this protocol, an interval record spreadsheet was created. The record sheet consisted of a $16 \times 30$ matrix. The 16 lines of the protocol presented the names of the behaviors defined in the observation protocol. The 30 columns corresponded to one-minute intervals at which a mark was made if the behavior at the line occurred during a given minute.

\section{Procedure}

After approval of the project by the ethics committee (CAAE process 59609916.00000.0029), the research began. Initially, an interview was conducted with the parents or guardian of the children. This interview aimed to collect data related to the student's history in general, scholar history, and the monitoring processes (medical, psychological, psych pedagogical) of the ADHD. The pre-selected students based on the indication of the coordinator, teachers and interview were evaluated with the Attention Deficit and Hyperactivity Disorder Scale (version for teachers), which was answered by the teacher of the participant. Among the indicated students, those with scores equal to or greater than 76 , in at least one of the three components of the Attention
Deficit and Hyperactivity Disorder Scale, were selected to participate in the research.

Before starting the data collection, habituation procedures (to the presence of the researcher and camera in the classroom) were adopted, since all sessions were fully filmed. In this sense, five sessions were held in each class of the three participants. In the first three sessions, the researcher remained in the classroom, just observing the activities performed. In the following two sessions, with the additional objective of adjusting the protocol for systematic observation of typical ADHD behaviors and preparing the researcher for the situation of data collection, the observation was accompanied by the recording of the behaviors. All these sessions, as well as the baseline and intervention sessions, described below, were held during class hours, prior to recess break and lasted 30 minutes.

A combined single-subject reversal design (ABA) and a multiple baseline between participants was used (Kazdin, 2011). The three participants were exposed alternately and successively to the baseline and intervention conditions. While Carlos and Fábio were exposed to the intervention, Bruno was exposed to the baseline. Then, when Carlos and Fábio were exposed to baseline, Bruno was exposed to the intervention condition.

Initially, all participants went through four baseline sessions. During these sessions, the researcher remained in the classroom and observed the behavior of the participants during the activities proposed by the teacher, which included written exercises without highlighted words.

The intervention was then introduced and maintained over four sessions for participants Carlos and Fábio, while Bruno continued to be observed at baseline for another four sessions. At the end of the application of the intervention with Carlos and Fábio, baseline was reestablished for them. Simultaneously, Bruno was exposed to the intervention for four sessions after which the baseline was reestablished.

The intervention was applied, collectively, to all students in each participant's class, to make it impossible to identify and discriminate participants (Carlos, Bruno and Fábio) by the other students. On the first day the intervention was applied, the researcher showed a series of slides with information and images about different animals in extinction while talking to students about the phenomenon of extinction, why it occurred, its causal agents and consequences in the present and in the future. Later, the researcher presented the first activity sheet, which was read collectively for everyone. After reading, students were asked to answer the questions in the activity sheet.

In the other three intervention sessions, the slide resource was not used, the researcher talked to the students about the animal that would be studied that day and the implications of the extinction of such animal in nature and in society. After this initial interaction, the researcher handed over the 
Table 2

Systematic Observation Protocol of Typical ADHD Behaviors (Reproduced as in Araújo et al., 2011)

\begin{tabular}{|c|c|c|}
\hline $\begin{array}{l}\text { Behavioral } \\
\text { Pattern }\end{array}$ & $\begin{array}{l}\text { Behavior } \\
\text { Classes }\end{array}$ & Characterization and Examples of Behaviors \\
\hline \multirow[t]{3}{*}{ Inattention } & $\begin{array}{l}\text { A - Looking away from } \\
\text { the teacher during the } \\
\text { explanation }\end{array}$ & $\begin{array}{l}\text { Any activity performed by the student during an explanation from the teacher that characterizes a } \\
\text { deviation from the teacher's gaze (e.g., lying down at the school desk, walking around the room, } \\
\text { fiddling with the backpack, talking to a colleague). }\end{array}$ \\
\hline & $\begin{array}{l}\text { B - Looking away from } \\
\text { the notebook }\end{array}$ & $\begin{array}{l}\text { Any activity performed by the student while performing a task that requires the notebook, but that } \\
\text { he does not use it (e.g., lying down at the school desk, walking around the room, fiddling with the } \\
\text { backpack, talking to a colleague). }\end{array}$ \\
\hline & $\begin{array}{l}\mathrm{C} \text { - Stopping responding } \\
\text { when asked }\end{array}$ & $\begin{array}{l}\text { Any activity performed when the teacher requests the student, but he does not respond when asked } \\
\text { (e.g., lying down at the school desk, walking around the room, fiddling with the backpack, talking to a } \\
\text { colleague). }\end{array}$ \\
\hline \multirow[t]{4}{*}{$\begin{array}{l}\text { Easily } \\
\text { Distracted }\end{array}$} & $\begin{array}{l}\mathrm{D}-\text { Engaging in events } \\
\text { other than classroom } \\
\text { activities }\end{array}$ & $\begin{array}{l}\text { Any activity performed by the student other than that requested by the teacher (e.g., fiddling with the } \\
\text { backpack when he should do an exercise, talking to colleague(s) instead of reading the text, walking } \\
\text { around the room instead of doing math). }\end{array}$ \\
\hline & $\begin{array}{l}\text { E - Exceeding the time set } \\
\text { for completing tasks }\end{array}$ & $\begin{array}{l}\text { Not completing tasks on time (e.g., when the teacher corrects an exercise in class and the student has } \\
\text { not finished it). }\end{array}$ \\
\hline & $\begin{array}{l}\text { F - Delay in starting } \\
\text { school tasks }\end{array}$ & $\begin{array}{l}\text { The student postpones the start of a task when the teacher asks students to perform it. Usually, these } \\
\text { behaviors are associated with others that prevent the performance of tasks, such as lying in the wallet, } \\
\text { walking around the room, touching the bag, talking to the colleague. }\end{array}$ \\
\hline & $\mathrm{G}$ - Losing things & $\begin{array}{l}\text { The student does not find the material when he needs it to carry out an activity (e.g., when the student } \\
\text { loses a pencil, eraser, or colored pencils, necessary to perform the task). }\end{array}$ \\
\hline \multirow[t]{4}{*}{ Restlessness } & $\begin{array}{l}\mathrm{H} \text { - Moving and squirm in } \\
\text { the chair }\end{array}$ & $\begin{array}{l}\text { Any student's movement (torso, head, or neck) during an explanation or school activity (e.g., shaking } \\
\text { the torso, neck, or head). }\end{array}$ \\
\hline & I - Moving hands and feet & $\begin{array}{l}\text { Any student's movement (feet or hands) during an explanation or school activity (e.g., shaking the feet } \\
\text { or moving the hands excessively). }\end{array}$ \\
\hline & $\mathrm{J}$ - Changing posture & $\begin{array}{l}\text { Any movement of the student during an explanation or school activity that makes him turn in his school } \\
\text { chair (e.g., turn to talk to a colleague behind him). }\end{array}$ \\
\hline & $\mathrm{K}$ - Talking too much & $\begin{array}{l}\text { Speaking in situations where he is expected to remain silent (e.g., speaking during the teacher's } \\
\text { explanation, speaking during the performance of individual tasks, speaking when others are speaking). }\end{array}$ \\
\hline \multirow[t]{2}{*}{ Movement } & $\begin{array}{l}\text { L- Getting up from the } \\
\text { chair }\end{array}$ & $\begin{array}{l}\text { Getting up from the school chair in situations where he is expected to remain seated (e.g., getting out of } \\
\text { the school chair during the teacher's explanation or while performing tasks). }\end{array}$ \\
\hline & $\begin{array}{l}\mathrm{M}-\text { Walking or running } \\
\text { in the room or leaving the } \\
\text { room }\end{array}$ & $\begin{array}{l}\text { Walking or running around the room, or getting out of the room in situations where he is expected to } \\
\text { remain seated (e.g., getting out of the school chair during the teacher's explanation or while performing } \\
\text { tasks; constantly asking to go to the bathroom or drink water). }\end{array}$ \\
\hline \multirow[t]{3}{*}{ Impulsivity } & $\begin{array}{l}\mathrm{N} \text { - Having difficulty } \\
\text { waiting for your turn }\end{array}$ & $\begin{array}{l}\text { Difficulty, when several students are asked to perform an activity, in waiting for his turn (e.g., the } \\
\text { student does not wait to be called when the teacher distributes material to a class; he does not wait for } \\
\text { his turn when several colleagues are asked to perform an activity on the blackboard). }\end{array}$ \\
\hline & $\begin{array}{l}\mathrm{O}-\text { Speaking without } \\
\text { being stimulated }\end{array}$ & $\begin{array}{l}\text { Speaking without being asked or authorized, or without being the right time (e.g., the teacher directs the } \\
\text { question to another student, but it is the participant who answers). }\end{array}$ \\
\hline & $\begin{array}{l}\text { P - Interrupting others' } \\
\text { speeches }\end{array}$ & $\begin{array}{l}\text { Intruding into a conversation without being asked or authorized (e.g., interrupts the teacher's } \\
\text { explanation, the colleague's question, or the conversation between colleagues). }\end{array}$ \\
\hline
\end{tabular}

activity sheet for the day, instructed the students to read it and answer all questions.

Each intervention session, after the distribution of the activity sheet to the students, lasted 30 minutes. During this period, the teacher monitored the class work while the researcher observed and recorded the participant's behaviors.
Throughout all sessions, participants' behaviors were recorded using the protocol for systematic observation of typical ADHD behaviors. Given the substantial number of behaviors observed simultaneously, at the end of the sessions, the researcher checked and adjusted the record based on the filming. 


\section{RESULTS}

In order to assess the reliability of the data, the agreement between observers was calculated for $25 \%$ of the sessions of each participant by comparing the on-site records, made by the researcher, with others made by an independent observer from the filming. For this purpose, one or two sessions were randomly selected from each baseline condition and intervention for each participant. Initially, the agreement between observers was calculated to each of the 16 behaviors by comparing the record of occurrence (or not) of a given behavior by the researcher and observer, every minute. Thus, if both had recorded the occurrence of the behavior in a given minute, it was counted as an agreement. If one had recorded the occurrence and the other had not, in a given minute, it was counted as a disagreement. Over the 30-minute session, the agreement and disagreement numbers could vary between zero and 30 for each behavior. From these numbers, the observer agreement index was calculated for each behavior. The overall inter observer agreement index (per session) was calculated from the average of the 16 indexes of the individual behaviors. These rates ranged from $75 \%$ to $100 \%$ with an overall average of $87.2 \%$.

Figure 2 shows the results of the three participants in all experimental sessions, with a total of 11 sessions for Carlos, 16 for Bruno and 12 for Fábio. These differences in the number of sessions are related to the fact that Bruno was exposed to four more baseline sessions compared to the other participants. Carlos, who should have done the same number of sessions as Fábio, left the room on the day of the first intervention session.

The abscissa axis shows the sessions sequentially, in the order they occurred, numbered from 1 to 16 . The ordinate axis shows the total occurrences of the behaviors of the Attention Deficit and Hyperactivity/Impulsivity classes divided by the number of behaviors that compose the class. This ratio corresponds, in the case of the Attention Deficit class (continuous curve), to the sum of the occurrences of

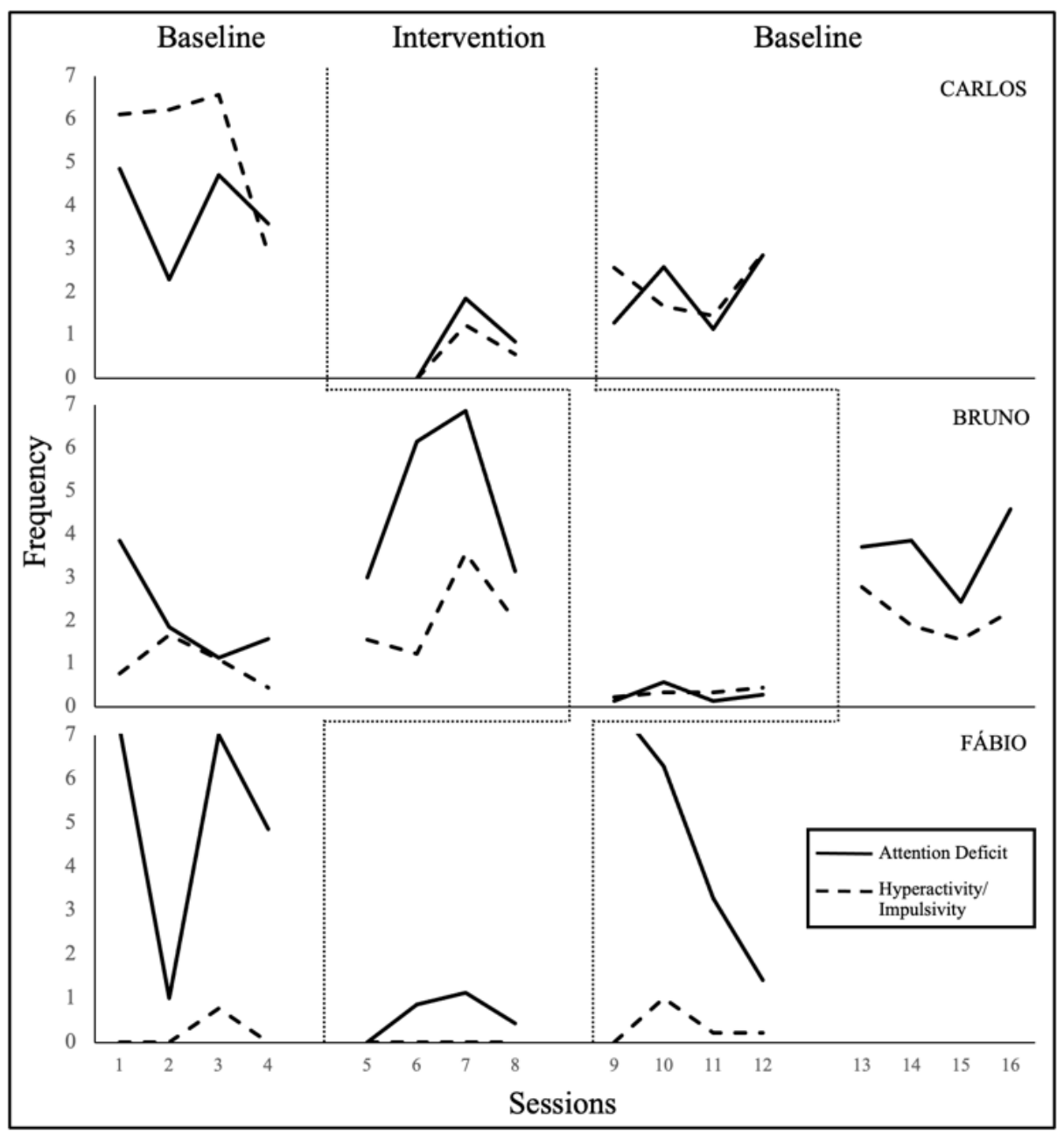

Figure 2. Frequency ratio of the Attention Deficit (continuous line) and Hyperactivity/Impulsivity (dashed line) behavior classes for each session of baseline and intervention conditions. 
each of the seven behaviors of the categories "inattention" and "easily distracted" (Table 2), divided by seven. For the Hyperactivity/Impulsivity class (dashed curve), the ratio resulted from the sum of the occurrences of the nine behaviors of the categories "restlessness", "movement" and "impulsivity" divided by nine. Thus, the greater the ratio, the greater the frequency of responses in the session.

In general, the data show variability, with higher frequencies of responses in the baseline sessions. In these sessions, the frequencies of the behaviors of the Attention Deficit class were higher than those of the Hyperactivity/ Impulsivity class for the participants Bruno and Fábio.

With the introduction of the intervention, the frequency of the behaviors of both classes decreased for all participants. For Carlos, who was exposed to only three intervention sessions, the frequencies of both classes were similar throughout the intervention. For Bruno and Fábio, however, the frequency of Hyperactivity/Impulsivity behaviors was always lower than that of Attention Deficit throughout the intervention; Fábio presented zero frequency for Hyperactivity/Impulsivity. With the reestablishment of the baseline, on the ninth (for Carlos and Fábio) or $13^{\text {th }}$ session (for Bruno), the frequency of the behaviors of both classes increased.

Figure 3 shows the percentage of correct responses for each of the participants, compared to the average percentage of correct responses for the other students in their corresponding classes, in the total of questions with and without highlighted words from the four activity sheets used during the intervention.

Carlos and Bruno, and the other students from the three classes, presented a higher percentage of correct responses in the questions with highlighted words than in the questions without highlighted words. Fábio was an exception: he achieved $100 \%$ correct when responding to questions with or without highlighted words.

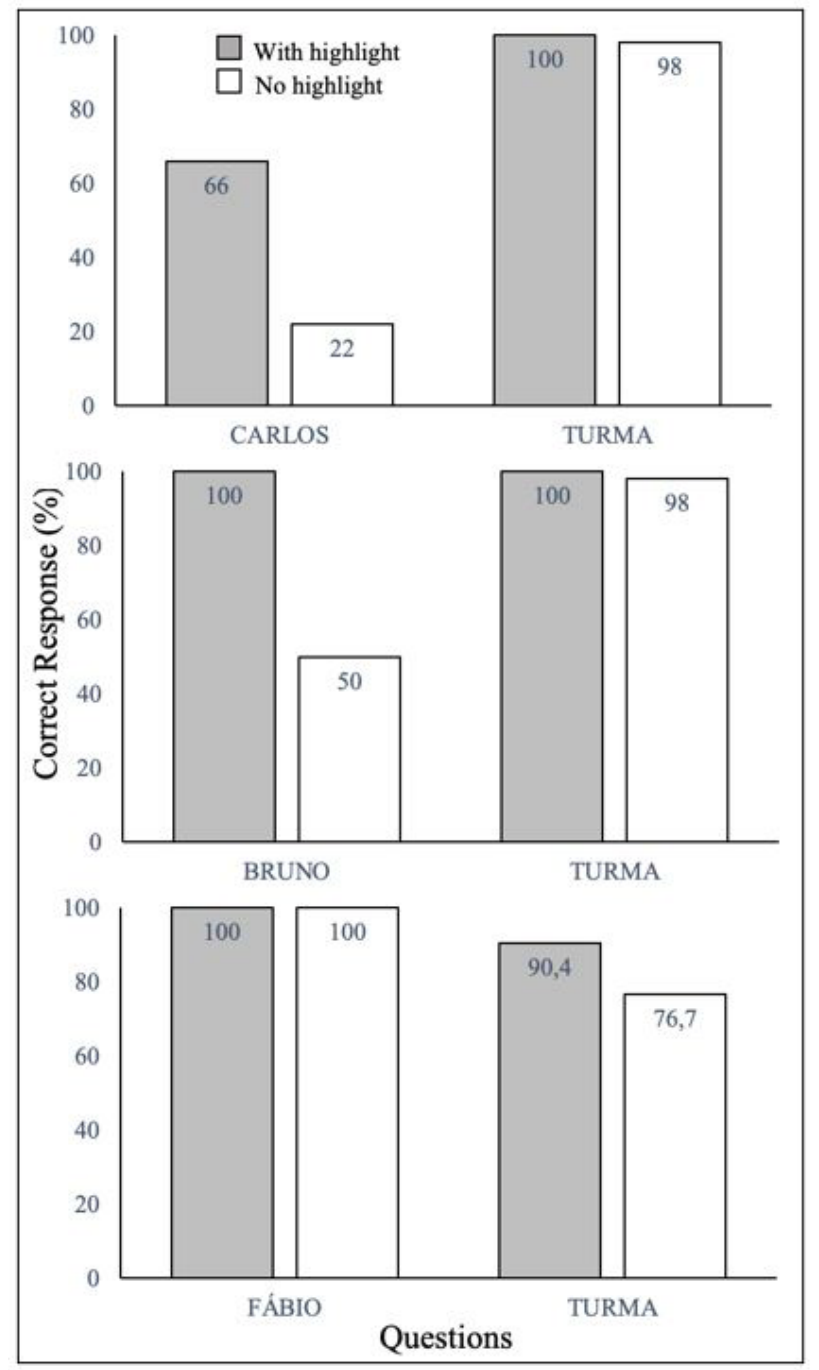

Figure 3. Percentage of correct answers by participants (bars on the left) and other students in their corresponding classes (bars on the right), in questions with (gray bars) and without (white bars) highlighted words.

\section{DISCUSSION}

The decrease in the frequencies of the Attention Deficit and Hyperactivity/Impulsivity behavior classes for the three participants, compared to the first baseline, suggests that the performance of tasks with highlighted words influenced these behaviors. Complementary evidence of the effect of the intervention is provided with the return to the baseline, when an increase in the frequency of the two behavioral classes is observed (Figure 2). The fact that the intervention reduced the frequency of the target behaviors of three different children, when applied in three different classroom contexts, since the participants were from three different classes and school years, and at different times, brings additional evidence of its effect.

It should also be considered that the intervention promoted the weakening of the characteristic behaviors of
ADHD, in the absence of coercive strategies (e.g., loss of concept points, notes in the agenda, assignment of extra tasks, deprivation of recess break), often used when the aim is to make such behaviors less frequent. These results are, therefore, empirical evidence of an alternative strategy to those coercive, which tend to generate harmful side effects to children and other people (Sidman, 2001).

The data on hyperactivity/impulsivity corroborate those of Zentall and Dwyer (1988). In this study, it was observed a decrease in the general activity of children with ADHD (measured directly by a device attached to the child's wrist, which recorded the child's activity in real time) when exposed to colored or black tasks of identifying different characteristics of two apparently identical figures. In the present study, on the other hand, there was a decrease in 
the frequency of hyperactivity/impulsivity behaviors (i.e., restlessness, movement, and hyperactivity), which was measured from observation (direct and by means of filming) and manual recording, when children were exposed to tasks with highlighted and not highlighted words.

In the study reported here, the effect of the intervention was also observed on the inattention repertoire, with a decrease in the frequency of the behaviors that compose this class. Effects of using color on attention have also been reported in other studies (e.g., Kercood et al., 2012; Zentall, 1985). Zentall (1985), for example, evaluated the effect of using colors in tasks of searching for a point in a matrix composed of 16 squares. In the "low stimulation" condition, the matrix was all gray, which required participants to look for the point in the entire matrix. Two conditions, called "high stimulation", used colored matrices. In one of these conditions, the point was presented in one of two blue squares, which reduced the participants' search area. In the other condition of "high stimulation", the color of the square, in which the point was presented, varied randomly. The performances of children with and without a diagnosis of ADHD were compared; children with ADHD made more mistakes in the condition of "low stimulation". In the condition of "high stimulation", the children of the two groups presented similar performances, with fewer errors than in the condition "low stimulation".

With regard to inattention, however, indirect measures, inferred from the correctness scores in the execution of a given task, are those predominantly used in research that investigates the highlight in color (Zentall \& Dwyer, 1988). In this sense, the results of the present study corroborate and expand those of previous researches as it assessed inattention by direct observation of the behaviors of the inattention and easily distracted classes, and also through the analysis of the percentages of correct answers to questions with and without words highlighted in yellow. With regard to this measure, higher percentages of correct responses were observed to the questions with highlighted words for the participants Carlos and Bruno. Similar results were presented by Kercood et al. (2012), in mathematical tasks, and by Belfiore et al. (1996), in textual understanding of children with attention deficit.

The percentage of correct responses presented by the other students in Bruno's and Carlos' classes and by Fábio differ from those of Bruno and Carlos. Those students presented similar percentage of correct responses, close to $100 \%$, in the questions with and without highlighted words. These data are similar to those presented by Zentall et al. (1985) related to the rates of errors committed by students with and without attention deficit when exposed to tasks of handwriting copy of texts with and without highlighting in color. In the study by Zentall et al. (1985) the highlighting in color reduced the error rates of students with attention deficit, but did not affect the performance of those without attention deficit.
In the case of Fábio, it is worth remembering that, despite being diagnosed with ADHD, he had low scores on the Attention Deficit and Hyperactivity/Impulsivity subscales of the Disability Disorder Scale Attention and Hyperactivity. The highest score presented by this participant (and which determined his inclusion in the research, given the requirement of scores equal to or greater than 76 in at least one of the subscales of the Attention Deficit and Hyperactivity Disorder Scale) was in the Anti-social Behavior subscale, which suggests a predominantly antisocial behavior pattern, but not inattentive or hyperactive/ impulsive. Thus, it is possible that academic impairments, commonly observed in children with ADHD and related mainly to inattention and hyperactivity/impulsivity, may be absent in Fábio, which is suggested by his high percentage of correct responses in questions with and without highlighted words. The results of Fábio's baseline, related to the Hyperactivity/Impulsivity class, support this possibility, since low and lower frequencies than those of the other participants are observed in all sessions. Regarding the Attention Deficit class, however, the same cannot be said, since the baseline results have high variability and higher frequencies than the other participants.

Researches that used color highlighting (e.g., Belfiore et al., 1996; Kercood \& Grskovic, 2009; Kercood et al., 2012; Zentall et al., 1985) had pointed out the role of this strategy as a promoter of selective attention. The highlight in color involves the handling of antecedent events to the behavior, thus constituting a stimulus control strategy (Sério et al., 2004; Skinner, 1976). This strategy increases the probability of the child paying attention to the highlighted information and, in doing so, emitting the correct answer in the task. Research using the prompt and involving the manipulation of stimulus salience (e.g., Ribes-Iñesta, 1980) presents robust data regarding the effect of these strategies in promoting accurate responses with different populations.

Additionally, the correctness of the task, in turn, works as a natural consequence that maintains the child's behavior. In this way, hyperactive/impulsive and inattentive behaviors are indirectly weakened by promoting and strengthening competing behaviors more appropriate to the classroom context. Ota and DuPaul (2002), in a study whose focus was on students' engagement and performance in mathematics tasks, found that as students' performance increased, the frequency of off task (motor, verbal and passive) behavior decreased.

Finally, the pragmatic and economic character of the word highlighting strategy stands out. This strategy can be easily applied in the classroom, with different contents, since it does not require material or human resources different from those usually available in the school context. The results point to its potential not only to promote better academic performance, but also to make disruptive behaviors typical of ADHD less likely. This type of research instrumentalizes the teacher to deal with students with ADHD, taking the 
teaching profession, directed to this public, from the field of intuition, increasing the probabilities of successful teaching.

Despite the differences observed between the frequencies of behaviors during the baseline and intervention for all participants and the higher percentages of success in academic tasks for two participants when the questions had highlighted words, the results of the present study should be viewed with reservations. It should be considered that, although the baseline and intervention sessions took place in the same context (classroom of each participant) and time (last class before recess), they were conducted by the teacher of the class and with the continuous presence from the researcher in class, the activities developed in the baseline sessions differed from those used in the intervention sessions in dimensions that extrapolated the presence or absence of words highlighted in colors (different content and structure). In this way, not only the highlighting of words, but also the structure of the task as a whole may have affected the performance of the participants. In this sense, similar studies, with the improvement of the control of strange variables, are important to increase the reliability and generality of the findings exposed here.

\section{REFERENCES}

American Psychiatric Association - APA (2014). Manual diagnóstico e estatístico de transtornos mentais (DSM-5) [Diagnostic and Statistical Manual of Mental Disorders] (5 ${ }^{\text {rd }}$ ed.). Artmed.

Araújo, M. V., Carvalho, A. M., Ribeiro, A. F., Teixeira, M. C. T. V., \& Carreiro, L. R. R. (2013). Manejo comportamental em classes de crianças com transtorno de déficit de atenção e hiperatividade. Interamerican Journal of Psychology, 47, 395-406. https://doi.org/10.30849/rip/ijp.v47i3.233

Araújo, M. V., Seraceni, M. F. F., Mariani, M. M. C., Lima, S. F. B., Teixeira, M. C. T. V., \& Carreiro, L. R. R. (2011). A observação como procedimento de avaliação direta de comportamentos de desatenção e hiperatividade no ambiente escolar [Observation as a Method for Direct Assessment of Inattention and Hyperactivity Behaviors in the School Environment]. Cadernos de Pós-Graduação em Distúrbios do Desenvolvimento, 11, 68-77.

Arruda, M. A., Almeida, M., Bigal, M. E., Polanczyk, G. V., MouraRibeiro, M. V., \& Golfeto, J. H. (2010). Projeto atenção Brasil: Saúde mental e desempenho escolar em crianças e adolescentes brasileiros. Análise dos resultados e recomendações para o educador com base em evidencias científicas [Atenção Brasil Project: Mental Health and School Performance in Brazilian Children and Adolescents. Analysis of Results and Recommendations Based on Scientific Evidence]. Instituto Glia.

Barkley, R. A. (2002). Transtorno de déficit de atenção/ hiperatividade - TDAH [Attention Deficit/Hyperactivity Disorder - ADHD]. Artes Médicas.

Belfiore, P. J., Grskovic, J. A., Murphy, A. M., \& Zentall, S. S. (1996). The effects of antecedent color on reading for students with learning disabilities and co-occurring attention-deficit/ hyperactivity disorder. Journal of Learning Disabilities, 29, 432-438. https://doi.org/10.1177/002221949602900411

Benczik, E. B. P. (2015). Transtorno de déficit de atenção/ hiperatividade: atualização diagnóstica e terapêutica: características, avaliação, diagnóstico e tratamento: um guia de orientação para profissionais [Attention Deficit/ Hyperactivity Disorder: Diagnostic and Therapeutic Update: Characteristics, Assessment, Diagnosis, and Treatment: A Guide for Professionals] ( $5^{\mathrm{a}}$ ed.) Casa do Psicólogo.

Cooper, J. O., Heron, T. E., \& Heward, W. L. (2007). Applied behavior analysis ( ${ }^{\text {rd }}$ ed.). Prentice-Hall.

Costa, C. R., Moreira, J. C. C., \& Seabra Júnior, M. O. (2015). Estratégias de ensino e recursos pedagógicos para o ensino de alunos com TDAH em aulas de educação física [Teaching Strategies and Pedagogical Resources for Teaching ADHD Students in Physical Education Classes]. Revista Brasileira de Educação Especial, 21, 126-126. https://doi.org/10.1590/ S1413-65382115000100008
Dinsmoor, J. A. (1995a). Stimulus control: Part I. The Behavior Analyst, 18, 51-68. https://doi.org/10.1007/BF03392691

Dinsmoor, J. A. (1995b). Stimulus control: Part II. The Behavior Analyst, 18, 253-269. https://doi.org/10.1007/BF03392712

Domjan, M. (2010). The principles of learning and behavior. Wadsworth Cengage Learning.

Dorneles, B. V., Corso, L. V., Costa, A. C., Pisacco, N. M. T., Sperafico, Y. L. S., \& Rohde, L. A. P. (2014). The impact of DSM-5 on the diagnosis of learning disorder in ADHD children and adolescents: A prevalence study. Psicologia: Reflexão e Crítica, 27, 759-767. https://doi.org/10.1590/16787153.2014274167

Fontana, R. D. S., Vasconcelos, M. M. D., Werner Jr, J., Góes, F. V. D., \& Liberal, E. F. (2007). ADHD prevalence in four Brazilian public schools. Arquivos de Neuro-Psiquiatria, 65, 134-137. http://dx.doi.org/10.1590/S0004-282X2007000100027

Imhof, M. (2004). Effects of color stimulation on handwriting performance of children with ADHD without and with additional learning disabilities. European Child \& Adolescent Psychiatry, 13, 191-198. https://doi.org:10.1007/s00787-0040371-5

Kazdin, A. E. (2011). Single-case research designs: Methods for clinical and applied settings. University Press.

Kercood S., \& Grskovic J. A. (2009). The effects of highlighting on math computation performance and off-task behavior of students with attention problems. Education and Treatment of Children, 32, 231-241. https://doi.org/10.1353/etc.0.0058

Kercood, S., Zentall, S., Vinh, M., \& Tom-Wright, K. (2012). Attentional cuing in math word problems for girls at-risk for ADHD and their peers in general education settings. Contemporary Educational Psychology, 37, 106-112. https:// doi.org/10.1016/j.cedpsych.2012.02.001

Kern, L., Choutka, C. M., \& Sokol, N. G. (2002). Assessment-based antecedent interventions used in natural settings to reduce challenging behavior: an analysis of the literature. Education \& Treatment of Children, 25, 113-130.

Leonardi, J. L., \& Rubano, D. R. (2012). Fundamentos empíricos da Análise do Comportamento Aplicada para o tratamento do transtorno de déficit de atenção e hiperatividade (TDAH) [Empirical Foundations of Applied Behavior Analysis for the Treatment of Attention Deficit-Hyperactivity Disorder (ADHD)]. Perspectivas em Análise do Comportamento, 3, 1-19. https://doi.org/10.18761/perspectivas.v3i1.73

Mattos, P. (2015). No mundo da lua: Perguntas e respostas sobre transtorno do déficit de atenção com hiperatividade em crianças, adolescentes e adultos [Head in the Clouds: Questions and Answers on Attention Deficit Hyperactivity Disorder in Children, Adolescents, and Adults] (16 $6^{\text {rd }}$ Ed.). ABDA. 
Mitenberger, R. G. (2012). Behavior modification: Principles \& procedures. Wadsworth Cencage Learning.

Moysés, M. A. A., \& Collares, C. A. L. (2013). O lado escuro da dislexia e do TDAH [The Dark Side of Dyslexia and ADHD]. In M. G. D. Facci \& M. E. E. M. Meira (Eds.). A exclusão dos incluidos ( $1^{\text {rd }}$ ed.). EDUEM.

Neef, N., \& Northup, J. (2007). Attention deficit-hyperactivity disorder. In P. Sturmey (Ed.), Functional analysis in clinical treatment (pp. 87-109). Elsevier.

Organização Mundial da Saúde - OMS (2016). Classificação de transtornos mentais e de comportamento da CID-10. Artmed.

Ota, K. R., \& DuPaul, G. J. (2002). Task engagement and mathematics performance in children with attention-deficit hyperactivity disorder: Effects of supplemental computer instruction. School Psychology Quarterly, 17(3), 242. https:// doi.org/10.1521/scpq.17.3.242.20881

Planty, M., Hussar, W., Snyder, T., Provasnik, S., Kena, G., Dinkes, R., KewalRamani, A., \& Kemp, J. (2008). The condition of education 2008 (NCES 2008-031). Washington (DC): National Center for Education Statistics, Institute of Education Sciences, U.S. Department of Education.

Ribes-Iñesta, E. (1980). Técnicas de modificação do comportamento: Aplicação ao atraso no desenvolvimento [Behavior Modification Techniques: Application to Developmental Delay] (D. P. Soares, Trad.). EPU. (Trabalho original publicado em 1972)

Santos, L. F., \& Vasconcelos, L. A. (2010). Transtorno do déficit de atenção e hiperatividade em crianças: Uma revisão interdisciplinar [Attention deficit hyperactivity disorder (ADHD) in children: an interdisciplinary review]. Psicologia: Teoria e Pesquisa, 26, 717-724. http://dx.doi.org/10.1590/ S0102-37722010000400015

Sério, T. M. A. P., Andery, M. A., Gioia, P. S., \& Micheletto, N. (2004). Controle de estímulos e comportamento operante: uma (nova) introdução [Stimulus control and operant behavior: a (new) introduction]. Educ.

Sidman, M. (2001). Coercion and its fallout (Revised Edition). Authors Cooperative.
Skinner, B. F. (1972). Tecnologia do ensino [The Technology of Teaching] (R. Azzi, Trad.). EPU. (Trabalho original publicado em 1968)

Skinner, B.F. (1976). About behaviorism. Vintage.

Vasconcelos, L.A. (2002). Análise comportamental do transtorno de déficit de atenção e hiperatividade: Implicações para avaliação e tratamento [Behavioral Analysis of Attention Deficit Hyperactivity Disorder: Implications for Assessment and Treatment]. In H. J. Guilhardi, M. B. B. P. Madi, P. P. Queiroz, \& M. C. Scoz (Orgs.), Sobre comportamento e cognição: Contribuições para a construção da teoria do comportamento (pp. 144-154). ESETec.

Vasconcelos, M., Werner, J., Jr., Malheiros, A. F. A., Lima, D.F. N., Santos, I. S. O, \& Barbosa, J. B. (2003). Prevalência do transtorno de déficit de atenção/hiperatividade numa escola pública primária [Attention deficit/hyperactivity disorder prevalence in an inner city elementary school]. Arquivos de Neuropsiquiatria, 61, 67-73. http://dx.doi.org/10.1590/S0004282X2003000100012

Zentall, S. S. (1985). Stimulus-control factors in search performance of hyperactive children. Journal of Learning Disabilities, 18 , 480-485.

Zentall, S. S., \& Dwyer, A. M. (1988). Color effects on the impulsivity and activity of hyperactive children. Journal of School Psychology, 27, 165-174. https://doi.org/10.1016/00224405(89)90004-6

Zentall, S. S., Falkenberg, S. D., \& Smith, L. D. (1985). Effects of color stimulation and information on the copying performance of attention-problem adolescents. Journal of Abnormal Child Psychology, 13, 501-511. https://dx.doi.org/10.1007/ BF00923137

Zentall, S. S., Grskovic, J., Javorsky, J., \& Hall, A. M. (2000). Effects of noninformational color on reading test performance of students with attention deficit hyperactivity disorder (ADHD). Diagnostique, 25, 129-146. https://doi. org/10.1177/073724770002500204

Zentall, S. S., \& Kruczek, T. (1988). The attraction of color for active attention problem children. Exceptional Children, 54, 357-362. https://doi.org/10.1177/001440298805400411 